American Journal of Environmental Sciences 6 (4): 344-349, 2010

ISSN 1553-345X

(C) 2010 Science Publications

\title{
A New Collaborative Pattern between Landscape Architects and Urban Designers in Environmental Design
}

\author{
Mostafa Behzadfar, Mohsen Faizi, Sina Razzaghi Asl and Behzad Haji Beiklou \\ Department of Architecture and Environmental Design, \\ Iran University of Science and Technology, Iran
}

\begin{abstract}
Problem statement: Nowadays professions such as architecture, landscape architecture and urban design are playing a unique role in environmental design process. Meanwhile architecture is being separated from two other majors: landscape architecture and urban design by paying so much attention to constructing buildings. Landscape architecture and urban design have parallel subjects and goals and both have the intention to improve the quality of urban open spaces. Approach: Since these two majors have partly the same approaches in confronting the topic of urban open spaces design, this study propounded the desirable method of collaboration between the professionals of these two majors. This research defined the role and position, each of these two professions have in the environmental design process by taking advantage of grounded theory procedure and the usage of content analysis, constant comparison and the questionnaire techniques. Results: Ideas found in this research were laying stress on the fact that by considering the three-level system from relations between the parameters: design/planning, control/co-ordination, management/policy making as the main common roles among the urban design and landscape architecture professionals, one can achieve the pattern of an efficient interaction. Conclusion: In this co-operation, landscape architects by preparing plans and implementing details and urban designers by making design structures and standards will obtain a supplemental role in the environmental design process.
\end{abstract}

Key words: Urban design, landscape architecture, environmental design, urban environment, collaborative pattern

\section{INTRODUCTION}

Various professions are involved in urban open spaces design throughout the cities. Architects, landscape architects and urban designers during the last century, have resorted to designing and reviewing all kinds of urban open spaces on different scales and by various approaches. While many of the academic courses and research articles in the world regard these majors as Specialty trends of a greater set called Environmental design.

Nowadays various professions have been segregated in environmental design. In design schools, students meet different professional roles. Since the job of landscape architects, urban designers and environmental designers' aims at urban open spaces, facing the approaches and collaboration between them in attitude towards urban space occurs as a bed of people existence and a united human life. On the one hand, literature review and the analysis of co-operation and the collaboration between these majors through the sources and the samples from different cases, indicate the loss of efficient and clear interaction between them. In the opinion of researchers, this is caused by the deficiency of clear and clarified approaches in attitude towards interaction and co-operation between the majors in confronting the urban open spaces. Therefore, by observing the concepts and professional roles of each major in urban design, this study is going to answer this underlying question that on the basis of "what roles and systematic stratums in environmental design is the optimum pattern of the interaction between the professionals of two majors being formed?"

\section{MATERIALS AND METHODS}

Collecting a set of data related to the role and the domain of the tasks of landscape architects and urban designers in order to define the collaborative relations, makes the existence of an appropriate method a necessity. A method by which, one can be led from a

Corresponding Author: Sina Razzaghi Asl, Department of Architecture and Environmental Design, Iran University of Science and Technology, Iran. Tel: 09125025808 Fax: 02122045625 
set of data to design the theory and suggested model. In other words, compiling the theory on the basis of data and extracting the professional roles and comparative methods in analyzing and concluding the results, call for the usage of "Grounded Theory" method in the research. On the basis of Glaser and Strauss (1967) method, the theory is extracted from systematic data, with or without the background questions. Grounded theory is a methodology that provides the logical and systematic process by collecting and analyzing a set of certain data in order to extract the data-based theory (Hunter and Kelly, 2008; Bloor and Wood, 2006), different approaches in collection and analysis of the data are used in this method, Such as Coding, constant comparison and theoretical sampling. In this research with the aid of constant comparison technique, classification of the roles and the responsibilities of the two majors: Urban design and landscape architecture is constantly evaluated and compared and the main items in order to compile the theory are extracted.

The purpose of this research, as mentioned before, is focusing on the observation of the role of landscape architects and urban designers in urban environmental design and proposals for a pattern from their relations with each other on the basis of professional roles and responsibilities. According to this principle, this research in addition to extracting the definite items from the literature review, takes advantage of the questionnaire method in collecting and analyzing the data.

Self-administered questionnaire on the basis of Dillman et al. (2008) method was e-mailed pilot and finally to the accessible landscape architecture and urban design professors and graduates in Iran. The reason of this assignment was their acquaintance and predominance over the professional business market and also their presence of the interactions of majors with other professionals of environmental design including architects and urban designers. This survey was sent to 335 people on Dec. 2009. About 65\% ( $n=$ 217) of the individuals sent back the questionnaires completely filled.

\section{RESULTS}

The presentation of definitions, goals and the main subjects of environmental design majors by many of the professionals are known as the most important nature recognition sources and professional procedures of both disciplines. Besides, studies in the areas of projects and practical domains and also theoretical publications of both majors on a worldwide scale indicate the growth and the development of landscape architects and urban designers' authorizations in the urban and meta-urban areas. Therefore, the factor: domain expansion and the type of activity is one of the main features about the interactions between the majors and the lack of attention to it is very common among the professionals (Krieger, 2009; Lang, 2005; Shirvani, 1985; Madanipour, 2006; Thompson, 1998; Razzaghi Asl et al., 2010).

Some reasons with economic, politic and cultural nature in urban design are justified, regarding to economic improvements of the cities and this is being continued. Thus, the urban form has been considered as a tool to attract the finance and specific groups of people and urban design career is to create an agreeable and qualified image which has caused improvement and growth to this major during the last decades (Golkar, 2003). Nowadays landscape performers are, at the moment working on design in various areas and on scales of small urban spaces to complete eco-systems (Beardsley, 2001). Nowadays, by improving the role and the position of urban design in professional architecture and urbanism societies, the areas of urban designers' activities have become much more clarified. Before the urban design science was brought up, all the public open spaces like: parks, urban open spaces and recreational places had been designed mostly by the architects and landscape architects. Therefore landscape architects were mainly successful in arriving at urban design objective which can be well defined as creating an appropriate place for everyone. Along with this definition, their role in the evolution of urban design and their contribution to create elegant and prosperous civic spaces in all over the world specially in Europe and US, should not be ignored (Lang, 2005).

Perception of each of these roles in urban open spaces design is essential for landscape architects and urban designers. Because of without understanding the professional roles of each major, there will be gaps in their functions. In order to gain a system of main factors and items, some of the partly extensive definitions of the majors are presented and their main roles and functions are being emphasized in the form of coding (Table 1).

According to the Table 1, roles of design, planning, managing, coordinating, leadership, balancing, policy making and conservation by the urban designers and landscape architects in order to creating urban spaces are being emphasized.

The presence of urban designer among other essential professions in providing urban renewal plans is not only as a designer, but also a coordinator. 
Table 1: Key concepts extracted from definitions and landscape/urban design themes related to professional roles

\begin{tabular}{ll}
\hline Definitions and themes & Key roles
\end{tabular}

The collaborative and multi-disciplinary process of shaping the physical setting for life in cities, towns and villages; the art of making places; design in an urban context (Cowan, 2005).

Landscape architecture is the art and science of planning and designing external space for

human use and enjoyment (Cowan, 2005)

Lynch specified the role of the urban designers as a designer of 3 products: project design,

system design and urban design.

With regarding to environmental quality features (space-place), urban design is a profession

which embarks on designing and urban planning and its open civic spaces (Behzadfar, 2009)

Landscape architecture is the combination of analysis, planning, design, management,

conservation and renovation of the land

A landscape architect needs to establish equilibrium among his/her creativity, environment and urban landscape and also between physical and perceptual capacity of the landscape.

The concept of equilibrium is the center of the architect's functional experiments (Bell, 1999)

Nowadays urban designers should have the ability to establish equilibrium among different groups which are for the benefits of the project.

Some of the professionals such as Micheal Worth, Motlotch have emphasized on the urban designer's management role in providing environmental quality, sense of place and urban renewal (Golkar, 2003)

In Fein and Crespi (1977) research in the title of landscape architects, in the subdivision of working with others, 5 parameters have been introduced which one of them refers to the role of environmental leadership and project management by landscape architects. Landscape architect, when ever needed, should have the ability to guide the teams from the majors (Fein and Crespi, 1977)

Landscape urbanism approach recommends some tools by which landscape architects will have the ability to deal with the city building again and also have a more politic and clarified role in the subjects of urbanization, public policy, development, urban design and environmental sustainability (Waldheim, 2006)

An urban designer's task is to provide an visual structure for architects and urban planners in a manner that can cure and coordinate their decisions (Moughtin and Shirley, 2005) Landscape architecture is interpreted as land analysis considering natural processes and reproducing them by designing according to social and human needs (Shirvani, 1984)

Planning, design, managing and conservation

Balancing

Leadership, managing

Policy making

Co-coordinating

Analyzing and design

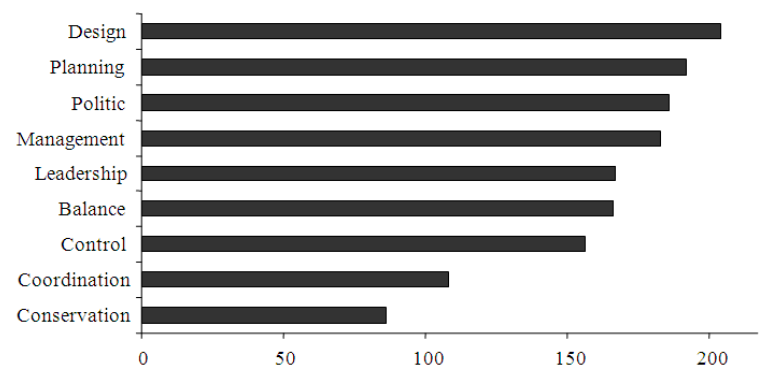

Fig. 1: Frequency of landscape architects and urban designers' professional roles in environmental design

This role is assigned to the urban designer not impose but naturally and logically. Urban designer attends the urban projects such as urban development plan as one the member of the team. However in providing the coordination and conduction documents and site-specific development projects, completes the role of the conductor, coordinator and manager the projects (Pakzad, 2007).

The answers to the first question, "in your opinion, what is the most important role of landscape architects and urban designers in urban environments?", totally are resulted in the form of Fig. 1. This question is generally asked and it's trying to find the main roles of the professional among the answers given.

In addition to eight-fold roles extracted from literature review, $71 \%$ of them $(n=156)$ referred to the controlling role of the two professions. More than half of the candidates have referred to controlling, balancing, conducting, managing, policy making, planning and design roles. Professionals have granted the most portions (94\%) to the design role.

Next question discovers the most important professional common roles between two majors in order to define the collaborative system between the professionals. Thus, it asks a question about it. Analysis and adding up the answers indicate the fact that managing, planning, policy making, conducting, design and controlling roles are the main professional common roles (Fig. 2). Meanwhile managing and planning roles, with the frequencies of 94 and $92 \%$ are the roles of great importance. And this implies that the main common professional aspects between these two majors are managing and planning.

Carmona et al. (2003) in the book, public placesurban spaces, regards the landscape architects as the professionals whose ultimate work is exterior design. 
Am. J. Environ. Sci., 6 (4): 344-349, 2010

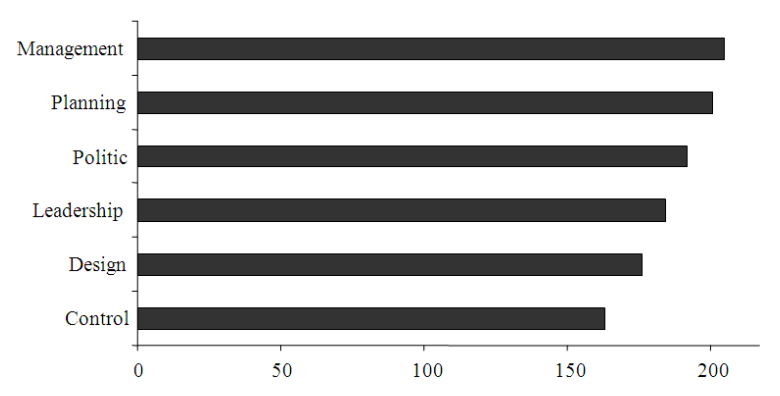

Fig. 2: Frequency of landscape architects and urban designers' common professional roles

According to this, urban design profession, proceed to compile the aims, policies and final design decisions in an urban area through some process. The role of urban designers can be defined in two ways: (1) intentional urban design and (2) inadvertent urban design. Therefore finally landscape architects will have the authority over all the plans in order to design urban open spaces and areas according to the plans. Alex Krieger (2009) writes about it:

"Landscape architecture is placed on the urban design area and the co-operation between Civil and ecology (Environment) majors lead to urban design. Thus, landscape architecture is an inseparable part of urban design process" (Krieger, 2009)

According to the functional system of landscape architects and urban designers, design and guidance are the products of urban design and landscape architecture. Each of them has a different rank of emphasis on the other products mentioned above. In case, subjects like Ecology and natural processes in landscape architecture and economy and society in urban design are regarded as the main emphasizes. But by appearing some approaches like green and ecological urban design and with regarding to social-economic dimensions of the landscape in landscape architecture, this professional distinction has been influenced; so that one can hardly tell apart the differences between the concerns and the approaches of these two majors. Urban design emphasizes on providing and presenting design guidance as a system of control and co-ordination while landscape architecture is more concerned about presenting the design and the detailed design of open space.

According to the text above, here comes the third question about the matter: "What is the main task of landscape architects and urban designers in formation of desired urban environments?".

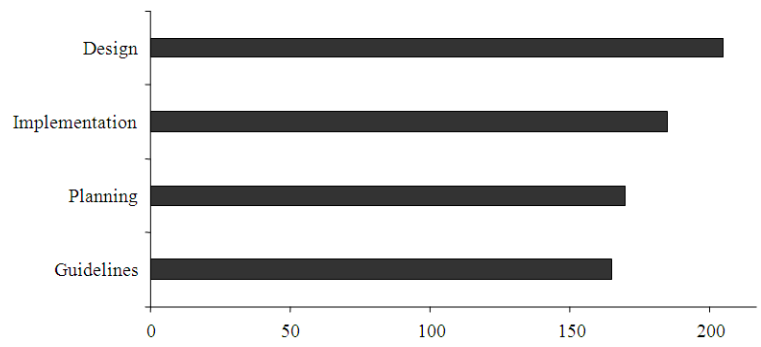

Fig. 3: Frequency of landscape architects' main tasks in environmental design

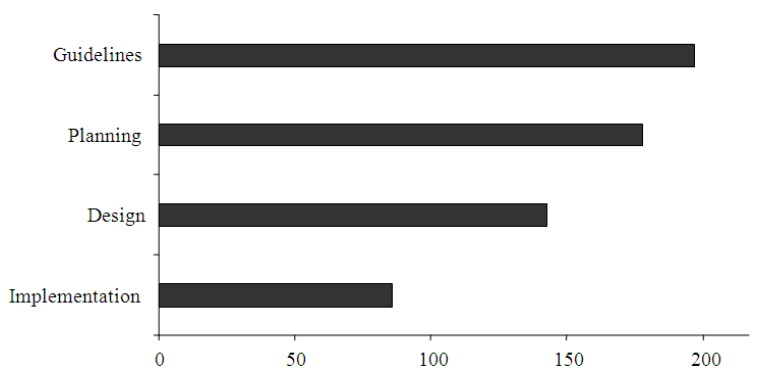

Fig. 4: Frequency of urban designers' main tasks in environmental design

Results show that landscape architects are expected to design $(\mathrm{n}=205)$, implementation $(\mathrm{n}=185)$, planning $(\mathrm{n}=170)$ and prepare guidelines and instructions ( $\mathrm{n}$ $=165$ ) in urban environments. Meanwhile the task of design with the frequency of $95 \%$ is much more important among landscape architects (Fig. 3).

Results on the subject of urban designers' main tasks, indicate the areas of guidelines $(\mathrm{n}=197)$, planning $(\mathrm{n}=178)$, design $(\mathrm{n}=143)$ and implementation $(\mathrm{n}=86)$ in urban environments. Meanwhile the task of preparing design guidance and instructions with the frequency of $90 \%$ is more important to the urban designers. Overemphasizing on the task of preparing guidance and planning according to deep and primitive connections between, urban planning and urban design majors and appearing "policy-oriented urban design" approaches and "designled planning" are justifiable and analyzable during recent decades (Fig. 4).

\section{DISCUSSION}

On the basis of final results from the questionnaires and professional contexts, Fig. 5 can be offered as a connection between landscape architecture and urban design professions along with their most important professional tasks (Fig. 5). 
Am. J. Environ. Sci., 6 (4): 344-349, 2010

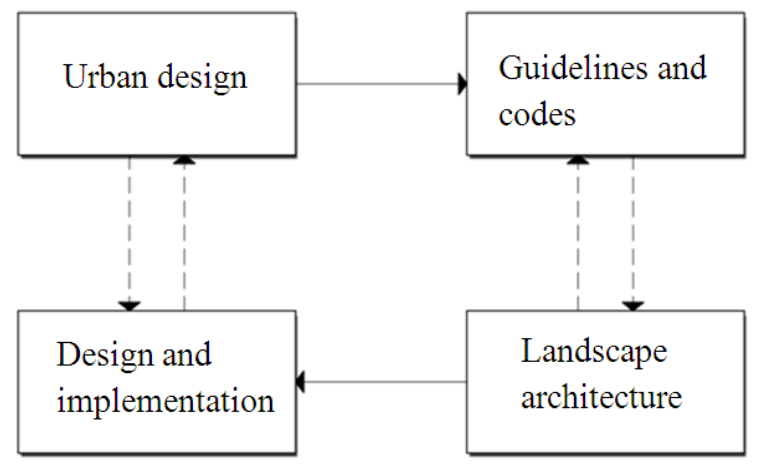

Fig. 5: The professional relationships between landscape architects and urban designers

Therefore, urban design will have a direct and effective role in preparing design guidance and landscape architecture is related to its design and implementing details. Besides, there is an indirect and less important relation about preparing design guidance by landscape architects and designing by urban designers (Carmona et al., 2003).

\section{CONCLUSION}

The last part of the study is being persisted by answering the basic question "on the basis of what roles and systematic stratums in environmental design is the optimum pattern of the interaction between the professionals of two majors being formed?". if we compare the activities of landscape architects and urban designers, urban designers because of having an holistic insight towards urban areas and places, compile approaches and present design proposals on large to small scales and pay attention to the integrated systems of urban environments, while landscape architects set about designing landscape details of the urban open spaces based on the extant form.

In this research, the most important roles and tasks of landscape architects and urban designers in confronting the urban environments have been extracted on the basis of reviewing and analyzing the landscape architecture and urban design texts and the experts' points of view. According to the approach of constant comparison to the literature and grounded theory method to data analysis, a pattern of collaboration has finally been defined based on the system of the roles and tasks. In this model based on different types of areas, projects and the main directions and concerns for urban design, all of the roles including coordinator, conductor, designer or controller in contact with each other, can be compiled. Of course this subject calls specific researches for itself.

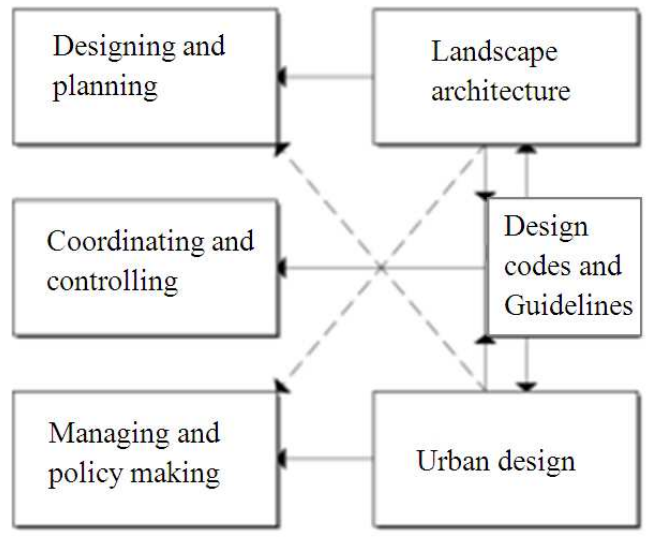

Fig. 6: Proposed collaborative pattern between landscape architects and urban designers

The results of this research show that a three-level system of the common roles of landscape architectures and urban designers including design/planning, coordinating/controlling and managing/policy making with regarding to their main tasks, can be considered as a pattern of the optimum collaboration between the professionals of the majors (Fig. 6).

According to Fig. 6, landscape architects on the one hand, do their professional tasks by preparing design guidance and codes and on the other hand, their main role for the landscape of urban environments, is designing and planning.

Urban designers also by their serious responsibility in compiling design guidance on one hand and their role in management and policy-making on the other hand, are involved in environmental design process. Meanwhile, the role of conduction and control belongs to both, landscape architects and urban designers and in both of them this role equally depends on the type and the content of the project and has a direct relation to the design guidance. Therefore, this study is trying to present a pattern of collaborations between urban design and landscape architecture in urban environmental design in a general model and by delineating the types of the relations between the roles and the tasks of the professionals.

\section{REFERENCES}

Beardsley, J., 2001. A Word for landscape architecture. Harv. Des. Mag., 12: 1-6.

Behzadfar, M., 2009. Designs and Plans in Urban Development. 1st Edn., City Publisher, Tehran, pp: 63.

Bell, S., 1999. Landscape: Pattern, Perception and Process. 1st Edn., Taylor and Francis, New York, ISBN: 13: 9780419203407, pp: 352. 
Bloor, M. and F. Wood, 2006. Keywords in Qualitative Methods: A Vocabulary of Research Concepts. 1st Edn., Sage Publications Ld., London, ISBN: 13: 9780761943303, pp: 208.

Carmona, M., T. Heath, T. Oc and S. Tiesdell, 2003. Public Places-Urban Spaces: The Dimensions of Urban Design. 1st Edn., Architectural Press, New York, ISBN: 0750636327, pp: 320.

Cowan, R., 2005. Dictionary of Urbanism. 1st Edn., Streetwise Press, London, ISBN: 10: 0954433009, pp: 468.

Dillman, D.A., J.D. Smyth and L.M. Christian, 2008. Mail and Telephone Surveys. 3rd Edn., Wiley, New York, ISBN: 13: 978-0471698685, pp: 512.

Fein, A. and I. Crespi, 1977. Landscape architecture among the design professions/a survey report. JAE, 31: 12-17.

Glaser, B.G. and A. Strauss, 1967. The Discovery of Grounded Theory. 1st Edn., Aldine, Chicago, ISBN: 13: 9780202302607, pp: 271.

Golkar, K., 2003. Urban design: From birth to maturity. SOFFEH, 36: 9-23.

Hunter, K. and J. Kelly, 2008. Grounded Theory. In: Advanced Research Methods in the Built Environment, Knight, A. and L. Ruddock (Eds.). Wiley, New York, ISBN: 9781405161107, pp: 86-98.

Krieger, A., 2009. Where and How Does Urban Design Happen. In: Urban Design, Krieger, A. and W.S. Saunders (Eds.). University of Minnesota, London, ISBN: 9780816656387, pp: 113-130.
Lang, J., 2005. Urban Design: A Typology of Procedures and Products. 1st Edn., Architectural Press, Sydney, ISBN: 13: 978-0750666282, pp: 400.

Madanipour, A., 2006. Roles and challenges of urban design. J. Urban Des., 11: 173-193. DOI: 10.1080/13574800600644035

Moughtin, J.C. and P. Shirley, 2005. Urban Design: Green Dimensions. 2nd Edn., Architecture Press, Oxford, ISBN: 9780750662079, pp: 272.

Pakzad, J., 2007. How the pioneers of urban design in Iran think. Q. J. Abadi, 17: 8-19.

Razzaghi Asl, S., M. Faizi and M. Behzadfar, 2010. Urban design and landscape architecture: Two professions, one goal? Environ. Sci. J., 7: 9-22.

Shirvani, H., 1984. The role of landscape architecture in urban design. J. Landscape Archit., 7: 12-21.

Shirvani, H., 1985. The Urban Design Process. 1st Edn., Van Nostrand Reinhold Company, New York, ISBN: 9780442280642, pp: 192.

Thompson, I., 1998. Landscape architecture and urban design: Two professions, one purpose. Urban Des. Q., 65: 1-7.

Waldheim, C., 2006. Landscape as Urbanism. In: The Landscape Urbanism Reader, Waldheim, C. (Ed.). Princeton Architectural Press, New York, ISBN: 9781568984391, pp: 35-54. 